\title{
A comparative analysis of NORs in diploid and triploid salmonids: implications with respect to the diploidization process occurring in this fish group
}

\author{
R. LOZANO,* C. RUIZ REJÓN† \& M. RUIZ REJÓN† \\ Departamento de Biologia Animal, Ecologia y Genética. *Escuela U. Politécnica de Almeria, Universidad de Granada. \\ 04120 Almeria, Spain and tFacultad de Ciencias, Universidad de Granada, 18071 Granada, Spain
}

\begin{abstract}
In order to study the way in which the process of genome diploidization involving salmonid fishes affects the ribosomal genes, chromosome location of active nucleolus organizer regions (NORs) was determined in diploid and triploid individuals of two species of salmonids - rainbow trout and coho salmon. These species belong to an aquaculturally important fish group of tetraploid ancestral origin. Diploids of both species show only one NOR-bearing chromosome pair, while new NOR sites, not detected in diploids, are observed in triploid karyotypes. However, the number of active NORs has not increased significantly with respect to the expected for the triploid level because some of the standard diploid NORs are repressed in triploids. Active NORs appear as $\mathrm{CMA}_{3}$-positive and DAPI-negative clusters in diploid and triploid karyotypes of both species. except the M3 type of rainbow trout which was observed only in triploid individuals. The data obtained suggest: (i) that diploidization of NORs still remains incomplete in the species of this group, and (ii) that the response of NOR-bearing chromosomes to fluorochromes can depend on changes between the inactivated and activated NOR-states associated with the triploidization. The variations in the rDNA of the NOR-type M3, which occur during the diploidization process, can account for the absence of response to fluorochrome staining. Other structural and evolutionary aspects regarding NORs are also discussed.
\end{abstract}

Keywords: diploid/triploid, genome diploidization, NORs, salmonid fishes.

\section{Introduction}

Polyploidy has played an important role in the evolution of plant (Lewis, 1980) and animal species, including fish (Ohno, 1970; Fisher et al., 1980; Bogart, 1980). Among the latter, salmonids form a group with a common ancestral tetraploid origin (see review by Allendorf \& Thorgaard, 1984; Johnson et al., 1987). Nevertheless, data based on isozyme loci inheritance, chromosome number and DNA quantities indicate the involvement of this group in a diploidization process, although it is quite difficult to know which parts of the genome have finished this process and which have not (Allendorf \& Thorgaard, 1984). Regarding ribosomal cistrons, it seems that some species of salmonids, such

Correspondence: Dr Rafael Lozano Ruiz, Department of Genetics, Faculty of Science, University of Granada, Spain. as salmonid trout, have retained the doubled number of rRNA genes (Schmidtke et al., 1976), but it is not known to what extent all of these genes are functional. In fact, from a cytogenetical point of view most salmonid species studied have two active NOR chromosomes, although some species have more than two (see reviews by Phillips \& Ihssen, 1985; Phillips $e t$ al., 1986a; Mayr et al., 1988). Some authors have found two NORs for rainbow trout whereas Mayr et al. (1986a, 1988) reported additional NOR regions. We considered the possibility that the new genetic background provided by induced triploidy could be of interest for the analysis of the diploidization process in rRNA genes and NORs. On this assumption, we compare the NORs of diploid and triploid specimens of rainbow trout and coho salmon. It is well known that artificial triploids can be obtained in some salmonid species by heat or cold shocks as well as by the action 
of chemical agents (see review of Thorgaard, 1986). On the other hand, to date, only non-thorough analysis of nucleoli numbers of triploid salmonids have been carried out (Phillips et al., 1986b). The appearance of some NOR sites in triploid specimens, but not in diploid specimens of both species, could be indicative of the fact that the diploidization process of NORs still remains incomplete in salmonids.

\section{Materials and methods}

\section{Animals}

The specimens of rainbow trout (Oncorhynchus mykiss) were grown at two Spanish fish farms located in Benamahoma (Cádiz) and Orol (Lugo). The coho salmon individuals (Oncorhynchus kisutch) originated in the latter. Diploid offspring were obtained for both species by standard fertilization and triploid offspring were obtained by preventing the extrusion of the second polar body in the normal egg by applying heat shocks shortly after fertilization (Lozano et al., 1988a). Progenitors of rainbow trout came from selected stocks of the above fish farms and parents of coho salmon were imported at the egg-stage from Oregon Aquafood (U.S.A.) in 1985. Both the diploid and triploid individuals analysed belonged to the same fertilization lot and therefore arose from the same progenitors.

\section{Cell suspensions and chromosome preparations}

Mitotic cells were obtained from two different kinds of tissue depending on the season and the laboratory equipment available in each fish farm. In some cases kidney tissue was used from live specimens previously treated with yeast solution and colchicine (Lozano et al., 1988b). On other occasions, 2-3 ml of blood were extracted from the dorsal vein and put into heparinized sterile tubes in order to perform lymphocyte cultures according to the technique described by Sánchez et al. (1990). To make chromosome preparations, one or two drops of the fixed cell suspensions (both from kidney and blood) were placed on cold-wet slides and allowed to dry in the air at room temperature.

\section{Chromosome banding}

The technique of Howell \& Black (1980) was employed to locate active NORs in metaphase cells. Fluorochrome banding with the two fluorochrome combinations chromomycin $\mathrm{A}_{3}$ /distamycin A (CMA) DA) and DAPI/actinomycin D (DAPI/AMD) was followed according to the methods reported by Schweizer $(1976,1979)$.

\section{Results}

\section{Rainbow trout}

The diploid individuals studied show a single NORbearing chromosome pair, metacentric of medium size with the NOR subterminally located. We labelled this as $\mathrm{M} 1$ (Fig. 1 a-c, e).

In the 28 triploid individuals analysed, three different types of NOR-bearing chromosomes can be identified (Fig. 1a and b): M1, which is identical to the type M1 described above for diploid metaphases; M2, which is also metacentric with subterminal NOR but shorter than M1; and M3, a metacentric chromosome larger than M1 and M2 and unlike these it shows the NOR at an interstitial position. Neither M2 nor M3 were observed in diploid individuals. The number of NORs per triploid genome can vary from two to four, the latter being the most frequent. Just a small number of combinations for all three M1, M2 and M3 were observed in our study (see Table 1). Combinations of two $\mathrm{M} 1$ and one $\mathrm{M} 1+$ one $\mathrm{M} 2$ have been observed among triploid metaphase cells with two NORs (Fig. 2a), three M1, two M1 + one M2, or two M1 + one M3 are the cytotypes seen in the cells with three NORs (Figs $1 \mathrm{e}$ and $2 \mathrm{~b}$ ), and plates containing four NORs show the combinations three $\mathrm{M} 1+$ one $\mathrm{M} 3$, or two $\mathrm{M} 1+$ one $\mathrm{M} 2+$ one $\mathrm{M} 3$ (Fig. 2c). The frequencies of each NOR cytotype for the two populations sampled are also shown in Table 1. The average number of nucleoli per cell increases significantly with the number of NORs, as expected. Note that of all the individuals with three NORs, the combination three M1 has the highest average number of nucleoli per cell.

On the other hand, NORs of rainbow trout diploids and triploids appear as CMA positive clusters in the active types $\mathrm{M} 1$ (Fig. 1b) and M2 but do not in the M3 type (Fig. 1a and d). DAPI staining shows clear gaps in the NORs located in M1 and M2 (DAPI- regions) and no differential staining in the NOR located in M3 (Fig. $1 \mathrm{~b}$ and $\mathbf{f})$. In addition, metaphase plates stained with DAPI/AMD display bright centromeric bands on several chromosome pairs (Fig. 1f).

\section{Coho salmon}

In chromosomes of diploid individuals, NORs were detected on the fifteenth metacentric pair (Figs 3 and 4a). This is involved in a chromosome polymorphism for duplications of the ribosomal cistrons because heteromorphism in the size and location of NORs was detected in homologues of metaphases from different individuals (Lozano et al., 1991).

All triploid coho salmon analysed have three NOR- 


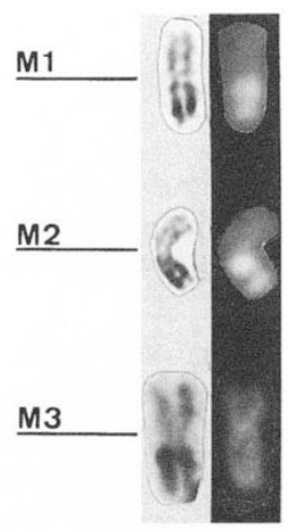

a

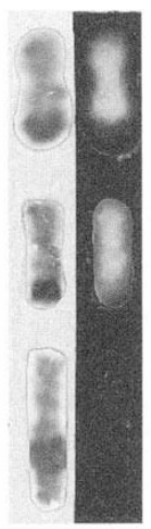

b
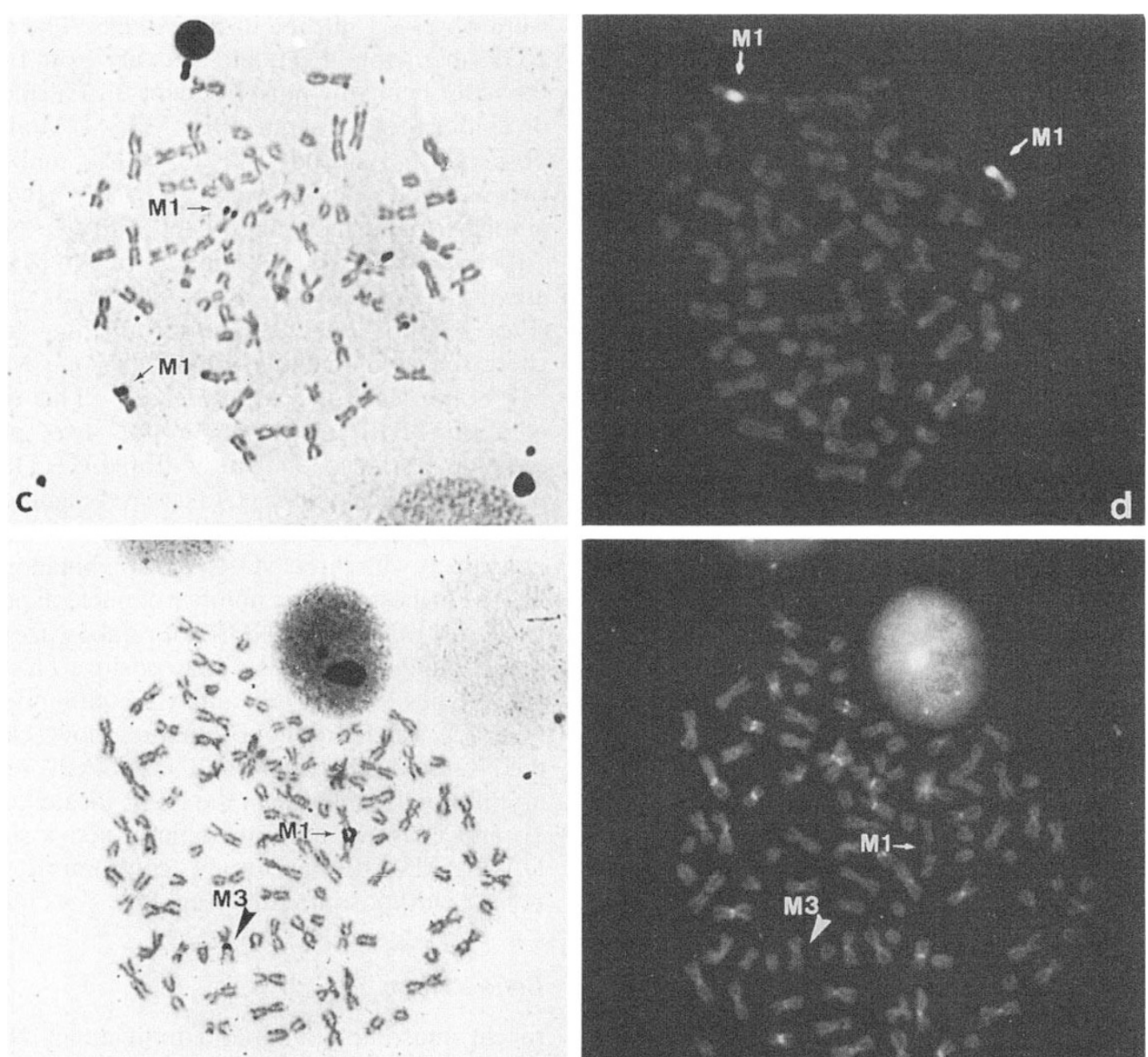

e

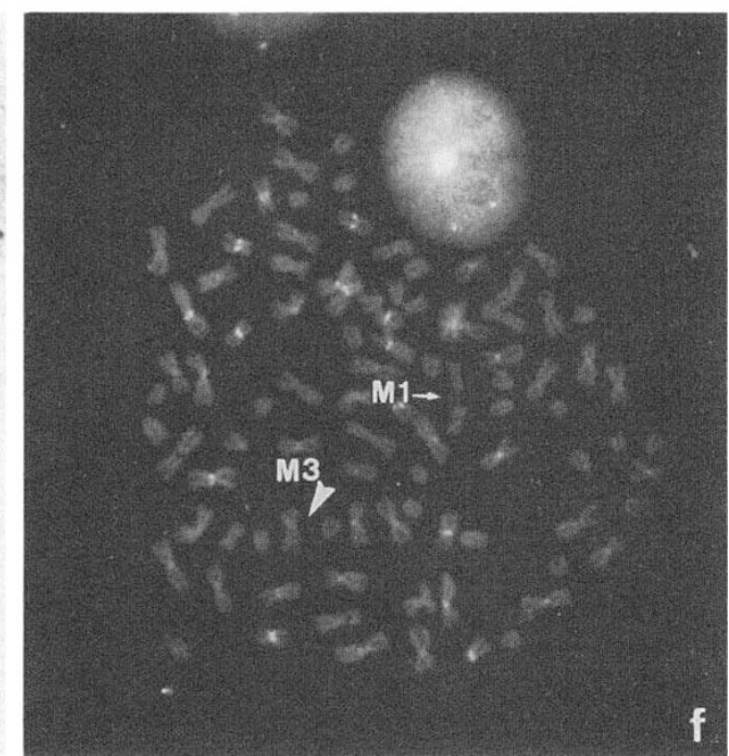

Fig. 1 NOR-bearing chromosome types observed in triploid individuals of Oncorhynchus mykiss after the two sequential staining Ag-CMA/DA (a) and Ag-DAPI/AMD (b). NORs (left) correspond to CMA ${ }^{+}$(a, right) and DAPI ${ }^{-}$(b, right) clusters except for the M3 type. Ag-stained (c) and CMA/DA stained (d) diploid metaphases showing the NORs (arrows), and sequential Ag-DAPI/AMD stained metaphase from a triploid individual of $O$. mykiss (e,f) showing the NOR-types M1 (arrows indicate two associated NORs) and M3 (arrowheads). 
Table 1 NOR variability in triploid individuals of rainbow trout from two Spanish fish farms

\begin{tabular}{|c|c|c|c|c|c|}
\hline \multirow[b]{2}{*}{ NOR-cytotype } & \multicolumn{2}{|c|}{ Frequency of cells } & \multirow{2}{*}{$\begin{array}{l}\text { Nucleoli/cell } \\
x+\text { s.d. }(n)\end{array}$} & \multirow[b]{2}{*}{$t_{\mathrm{s}}$} & \multirow[b]{2}{*}{$S$} \\
\hline & Benamahoma & Orol & & & \\
\hline $2 \mathrm{M} 1$ and $1 \mathrm{M} 1+1 \mathrm{M} 2$ & 13.33 & 10.00 & $1.46 \pm 0.08(54)$ & & \\
\hline $2 \mathrm{M} 1+1 \mathrm{M} 2$ & 20.00 & 20.00 & $2.59 \pm 0.10(44)$ & 039 & $\mathrm{~ns}$ \\
\hline $2 \mathrm{M} 1+1 \mathrm{M} 3$ & 6.67 & 10.00 & $2.54 \pm 0.08(30)$ & 2.67 & $* *$ \\
\hline $3 \mathrm{M} 1$ & 26.67 & 10.00 & $2.97 \pm 0.14(35)$ & 2.66 & $* *$ \\
\hline $\begin{array}{c}2 \mathrm{M} 1+1 \mathrm{M} 2+1 \mathrm{M} 3 \\
\text { and } 3 \mathrm{M} 1+1 \mathrm{M} 3\end{array}$ & 33.33 & 50.00 & $3.42 \pm 0.12(36)$ & & \\
\hline
\end{tabular}

$t_{\varsigma}=$ Student's $t$-test.

$S=$ level of significance.

n.s. no significant.

** $0.01>P>0.001$.

*** $P<0.001$.

bearing chromosomes. Ribosomal cistrons are located on three metacentric chromosomes, two of which are similar to those observed in diploid individuals; the third one is also metacentric but carries a NOR active region at a pericentromeric position (Figs 3 and $4 b$ ). This last NOR chromosome has never been seen in metaphase cells of diploid individuals from the same fertilization lot. The average number of nucleoli per cell is significantly higher for triploids $(2.75 \pm 0.10)$ than for diploids $\left(1.63 \pm 0.07, t_{\mathrm{s}}=9.175, P<0.0 .05\right)$. Active NORs appear as CMA positive clusters in both diploid and triploid individuals, while DAPI staining generates a negative response from these regions (Figs 3 and $4 \mathrm{c}$ and $\mathrm{d})$.

\section{Discussion}

Like other salmonid species, the diploid specimens of rainbow trout and coho salmon are carriers of two active NOR chromosomes. This number of NORs agrees with previous reports (Schmid et al., 1982; Phillips \& Ihssen, 1985). However, Mayr et al. (1986a, 1988), using a different technique of silver staining, found several NOR-bearing chromosome in addition to the expected pair (we call it M1) in rainbow trout. Other species of the same group have also been found to contain more than two active NORs (Phillips \& Ihssen, 1985; Phillips et al., 1986a, 1988, 1989; Mayr et al., 1988).

NORs of salmonid fishes are particularly variable regions frequently involved in chromosome poly- morphisms and heteromorphisms (see for example Mayr et al., 1988; Phillips et al., 1988; Sánchez et al., 1990). Thus, different polymorphic variants for duplications affecting the NOR-bearing chromosome pair have been described by us in diploid coho salmon (Lozano et al., 1991). On the other hand, we have not detected NOR variability in diploid rainbow trout, results which are consistent with those reported by others (Schmid et al., 1982; Phillips \& Ihssen, 1985).

Both types of observation (variability in number and size of NORs) could be related to the ancestral tetraploid origin of this group of fish. It seems reasonable that the ribosomal activity required in these diploid fish of polyploid origin could be achieved by two different mechanisms: duplicating the active NOR sites previously existing or increasing the number of NORcarrier chromosomes, i.e. activating some of the repressed NOR present in the ancestral tetraploid karyotype. Whether the amount of rDNA is increased by duplication of ribosomal cistrons in the same active chromosome or by activation of some repressed NORs in different chromosomes is unknown. Nevertheless, some reports suggest that there is a possibility of the diploid genomes of salmonids retaining the doubled number of rRNA genes (Schmidtke et al., 1976).

The suggestion that some repressed NOR-bearing chromosome still remain in diploid karyotypes of salmonid species, i.e. the occurrence of nucleolar dominance, could be related to the fact that this ploidy level has an allotetraploid ancestral origin, as demonstrated by Johnson et al. (1987). We therefore consider 

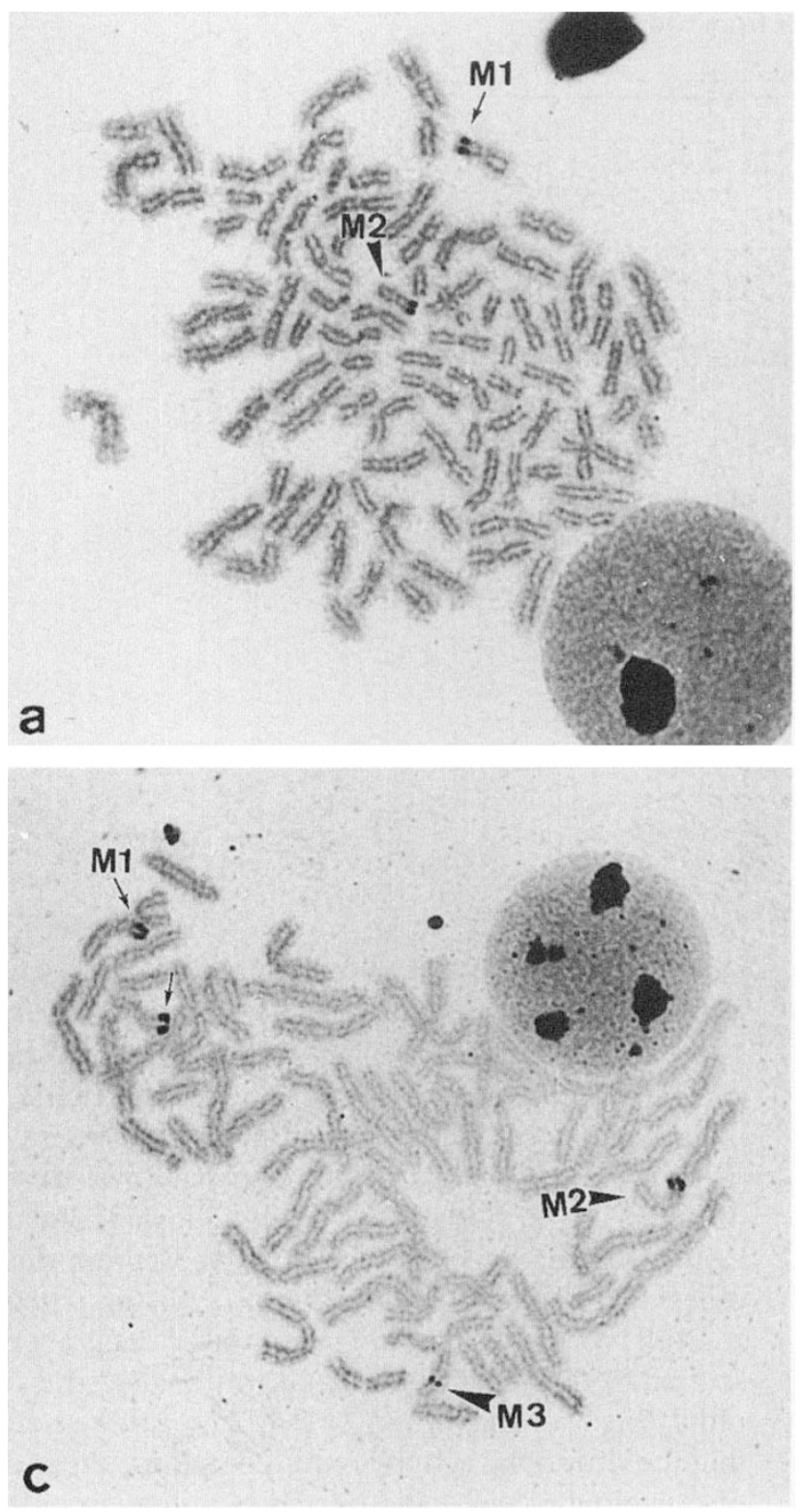

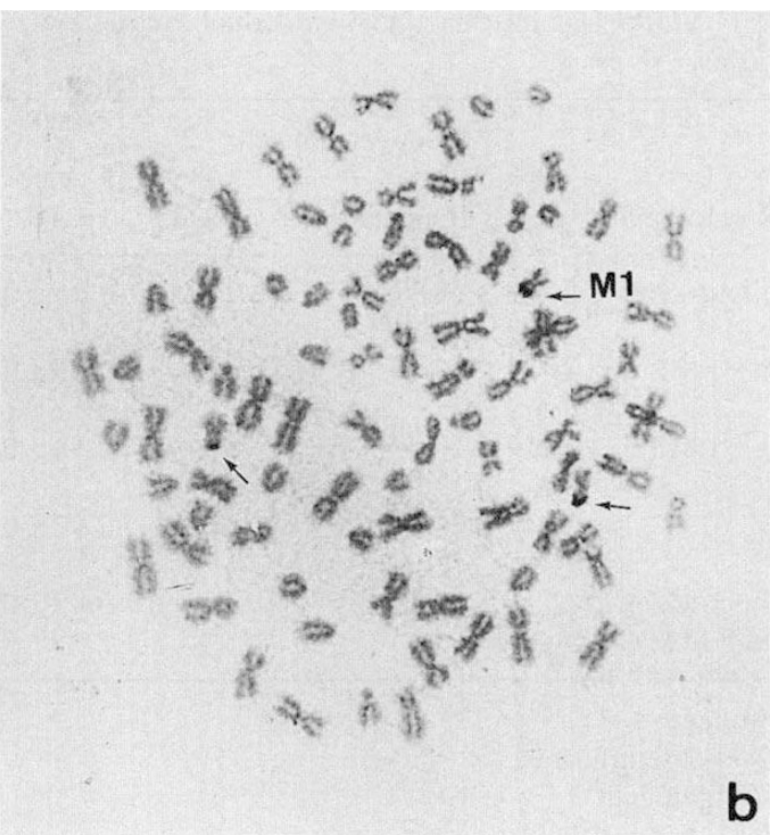

Fig. 2 Metaphase cells of three triploid individuals of Oncorhynchus mykiss carriers of different NOR-chromosome combinations: one $\mathrm{M} 1+$ one $\mathrm{M} 2$ (a), three $\mathrm{M} 1$ (b) and two $\mathrm{M} 1+$ one $\mathrm{M} 2+$ one $\mathrm{M} 3$ (c). NORs are marked by arrows (M1), small arrowhead (M2) and large arrowhead (M3), respectively. our observation of active NORs apparently originating 'de novo' in triploid individuals of the two species analysed in this work to be significant. The results of the cytogenetical analysis (Ag- and fluorochrome staining) indicate (i) that two new NORs, not present at diploid level, have been visualized in triploid individuals of $O$. mykiss (see Figs 1 and 2) and (ii) that in triploid specimens of $O$. kisutch there is one NOR located on a metacentric chromosome which is different to the standard NOR-bearing chromosomes of their corresponding diploids (see Figs 3 and 4). It is reasonable to think that in the new genetic background, generated in salmonids by the induced triploidy, some new NORbearing chromosomes appear as a result of the depression of inactivated NORs of the ancestral tetraploid karyotype.
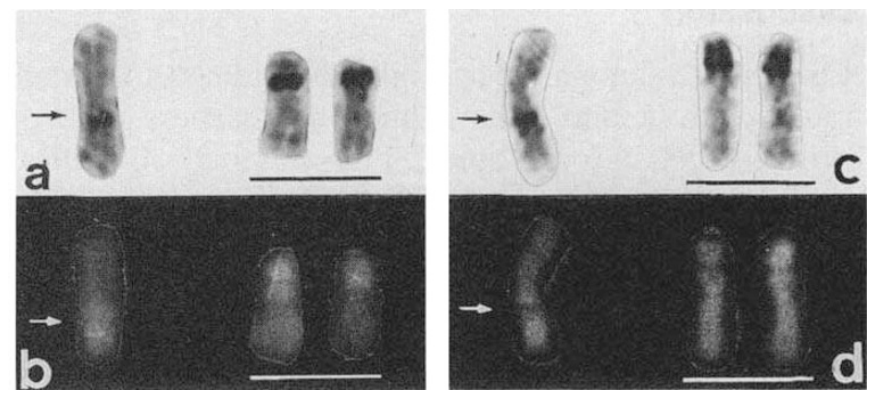

Fig. 3 Partial karyotype of two triploid individuals of Oncorhynchus kisutch sequential Ag-CMA/DA stained the first $(\mathrm{a}, \mathrm{b})$ and sequential Ag-DAPI/AMD stained the second (c, d). In addition to the standard NOR-chromosome pair (underlined), which is also present in diploid karyotypes, a 'new' NOR type is observed in triploid ones (arrows). 


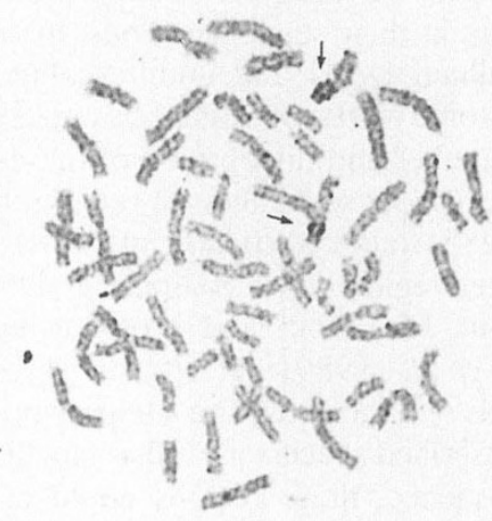

a

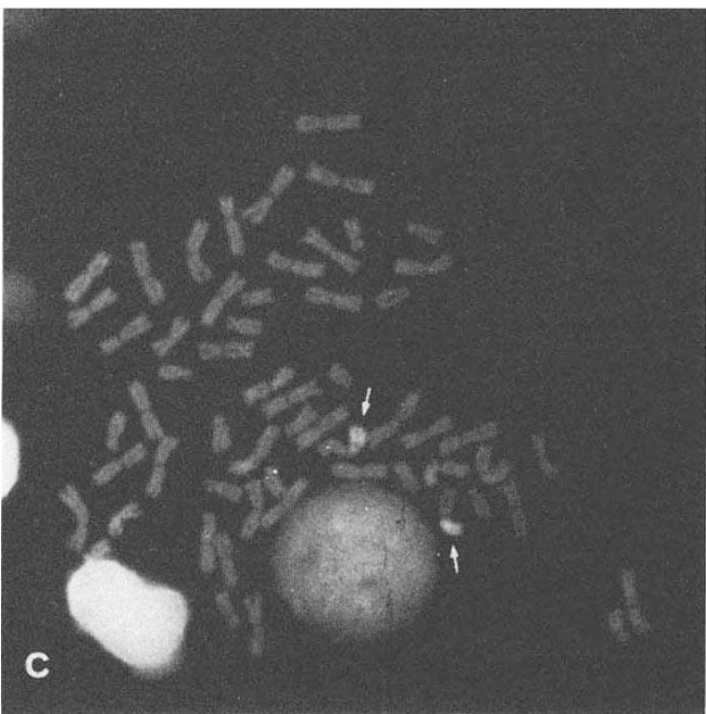

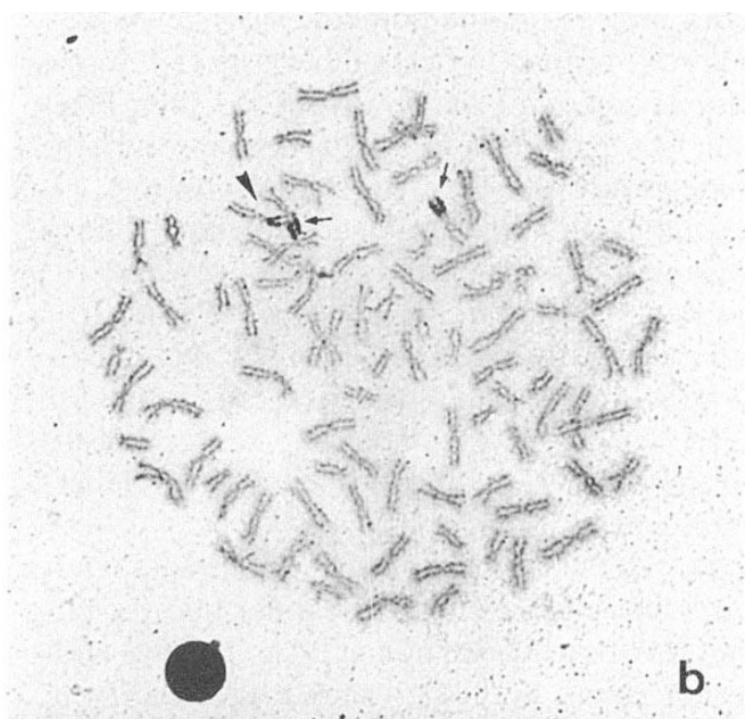

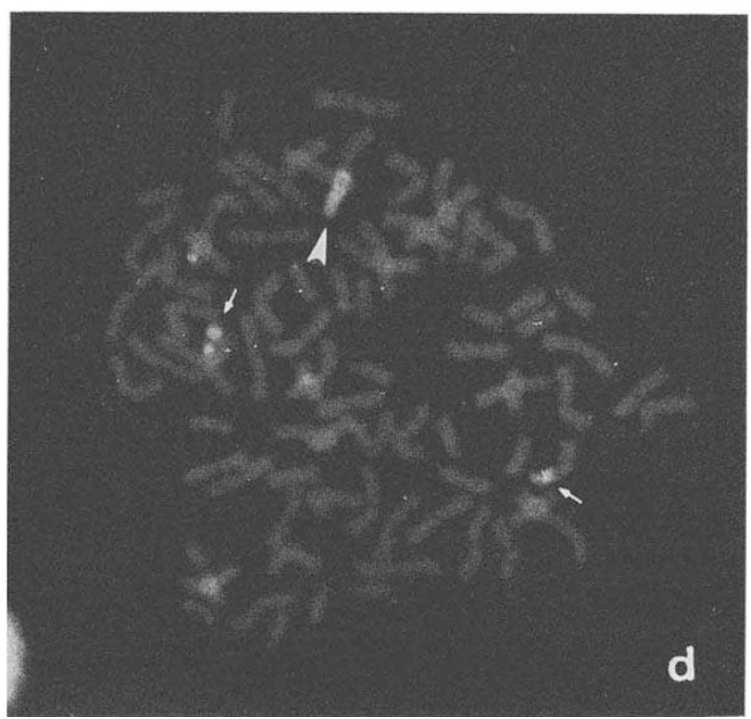

Fig. 4 Metaphase cells of diploid $(\mathrm{a}, \mathrm{c})$ and triploid $(\mathrm{b}, \mathrm{d})$ individuals of Oncorhynchus kisutch after $\mathrm{Ag}-(\mathrm{a}, \mathrm{b})$ and $\mathrm{CMA}_{3} / \mathrm{DA}$ (c,d) staining. Arrows indicate the standard NOR chromosomes and arrowheads indicate the 'new' NOR appearing in triploid individuals.

Similar results have been found by Thompson \& Flavell (1988) in hybrids of cereals in which the activation of certain ribosomal genes depends on their genetic background. It is interesting that, in the case of triploids of coho salmon and rainbow trout, the new NOR site located near the centromere of a large metacentric chromosome is similarly placed to those on both their homologues of other salmonid species within the same genus, Oncorhynchus gorbuscha (Phillips et al., 1986a). This could be a NOR-bearing chromosome which was present in the common salmonid ancestor and lies inactive in several species of the group. In fact, some of the additional NOR chromosomes observed in some populations of rainbow trout by Mayr et al. (1988), are also very similar to this type of chromosome.
The presence of new NOR-bearing chromosomes in induced triploid individuals, the existence of NOR variability in diploid and triploid genomes, and the high number of rRNA genes are indicative that the diploidization process of the NORs still remains incomplete in salmonid fish. Similar features also occur in some cyprinid fish species of tetraploid origin (Mayr et al., 1986 b). Furthermore, the suggestion that in the karyotype of salmonids some mechanism of nucleolar dominance persists (due to its ancestral allotetraploid origin) is supported by recent findings by Gold et al. (1991) regarding this existence of such kind of phenomena in interspecific hybrids of cyprinid fish.

It is worth mentioning, however, that the appearance 'de novo' of some NOR-bearing chromosomes in the triploid karyotypes of both species analysed does not 
determine an increase in the number of active NORs and nucleoli with respect to the number expected from its ploidy level (except for rainbow trout M3 site). This is due to the fact that in the triploid specimens of both species some of the standard NOR-chromosomes of the corresponding diploids have been repressed. Thus, triploids of coho salmon have only two active standard NORs and not three, as might be expected, and triploids of rainbow trout have normally one or two standard NORs present (see Table 1). It seems reasonable, therefore, to search for a compensatory mechanism which operates on triploid NORs to adjust the number of active NORs expected from its ploidy level.

The active NOR regions present in diploid and triploid karyotypes generally show similar fluorescent banding patterns, corresponding to $\mathrm{CMA}_{3}$-positive and DAPI-negative areas, with the exception of the type M3 found in triploid rainbow trout which does not show affinity with either of the fluorochromes used. Similarly, it seems that the response to fluorochromes of the NOR-bearing chromosomes can change between the inactivated and activated status. This also happens with the additional NORs observed here in triploid karyotypes and with some of the standard diploid NORs, which are inactivated at triploid level. It is known that the response to fluorochromes of chromosomal regions depends not only on DNA composition but also on specific acid proteins (Stockert et al., 1976; Hernández-Verdun, 1986) and because active NORs are associated with some particular proteins (Flavell et al., 1986; Moreno et al., 1990), we think that the non-appearance of bright fluorescence clusters in some standard NOR-chromosomes of both species at triploid level may be caused by the absence of those proteins. Their presence could explain the bright fluorescent regions observed on both the M2type of rainbow trout and the 'new' NOR-bearing chromosome identified in triploid coho salmons.

With regard to the M3 of rainbow trout, we think that the loss of the $\mathrm{CMA}_{3}$-positive character could be due to the true disappearance of the GC-rich clusters, normally NOR-associated. Thus, it is worthwhile mentioning that Mayr et al. (1988) observed positively DAPI-stained clusters (AT-rich regions) in the nonstandard NORs of the rainbow trout, and that we did not find, after treatments of triploid rainbow trout chromosomes with $\mathrm{CMA}_{3}$ or DAPI, any fluorescence differential staining along the NOR-type M3. It is thought that $\mathrm{CMA}_{3}$ stains the NORs because of its affinity for GC-rich sequences located in the nontranscribed spacers of rDNA (Brown et al., 1972; Schmid et al., 1982). It is possible, therefore, that during the diploidization process of salmonid genomes the inactivation of some NORs produces changes in the rDNA base sequence, the non-transcribed spacers (variable regions which evolve faster than coding regions) gain AT-base pairs while loosing some GCbase pairs in their sequence. Thus, the appearance of both brilliant DAPI and undifferentiated fluorescent areas in some NORs of salmonids could be determined by the number and distribution of these AT-base pairs along the spacer sequences. In relation to this, Popodi et al. (1985) found restriction-site differences between the spacer region when comparing rDNA from rainbow trout, lake trout and brook trout. In addition, Phillips et al. (1989) detected in several species of salmonids several restriction site polymorphisms in the non-transcribed spacers as well as length variability. As a consequence, these regions could have played an essential role in the evolution of rDNA cistrons in fish, similar to those in other vertebrate groups (Ohno, 1970; Bogart, 1980).

\section{Acknowlegdements}

We wish to thank Mr Fernando Nieto and Mr Alberto Chacón for taking care of the fish and for providing samples. Thanks are also due to Dr Laura Sánchez and Ms Ana Viñas for technical assistance. This work was supported by a grant from the Spanish CICYT (No. MAR90-0688) as well as from the Plan Andaluz de Investigación(Group No. 3186).

\section{References}

ALLENDORF, F. W. AND THORGAARD, G. H. 1984. Tetraploidy and the evolution of salmonid fishes, In: Turner, B. J. (ed.) Evolutionary Genetics of Fishes, Plenum Press, New York, pp. 1-53.

BOGART, J. P. 1990. Polyploidy in evolution of amphibians and reptiles. In: Lewis, H. L. (ed.) Polyploidy: Biological Relevance, Plenum Press, New York, pp. 341-369.

BROWN, D. D., WENSINK, P. C. AND JORDAN, E. A. 1972. A comparison of the ribosomal DNAs of Xenopus laevis and Xenopus mulleri: the evolution of tandem genes. J. Mol. Biol., 63, 57-73.

FISHER, S. D., SHAKLEE, J. B., FERRIS, S. D. AND WHITT, G. S. 1980. Evolution of five multilocus isozyme systems in the chordates. Genetica, 52, 73-85.

FLAVELL, R. B. AND O'DELL, M. THOMPSON, W. F. VINCENTZ, M. SARDANA, R. AND BARKER, R. F. 1986. The differential expression of ribosomal RNA genes. Phil. Trans. R. Soc. Lond. B., 314, 385-397.

GOLD, J. R. 1991. Nucleolar dominance in interspecific hybrids of cyprinid fishes. Cytobios, 65, 139-147.

HERNANDEZ-VERDUN D. 1986. Structural organization of the nucleolus in mammalian cells. Meth. Arch. Exp. Pathol, 12, 26.

HOWELL, W. M. AND BLACK, D. A. 1980. Controlled silver-staining of nucleolus organizer regions with a protective colloidal 
developer: a 1-step method. Experientia, 36, 1014-1015.

JOHNSON, K. R. WRIGHT, J. E. JR. AND MAY, B. 1987. Linkage relationships reflecting ancestral tetraploidy in salmonid fish. Genetics, 116, 579-591.

LEwIS, w. H.(ed.) 1980. Polyploidy: Biological Relevance. Plenum Press, New York.

LOZANO, R., RUIZ REJON, C. AND RUIZ REJON, M. 1988a. Obtención artificial de triploides en la trucha arco-iris (Salmo gairdneri Rich.) mediante choque térmico. I. Eficacia del método y supervivencia de la progenie. Genét. Ibérica, $\mathbf{4 0}$, 1-12.

LOZANO, R, RUIZ REJON, C. AND RUIZ REJON, M. 1988b. A method for increasing the number of mitoses available for cytogenetic analysis in rainbow trout. Stain Technol., 63, 335-338.

LOZANO, R., RUIZ REJÓN, C. AND RUIZ REJON, M. 1991. An analysis of coho salmon chromatin by means of C-banding, Agand fluorochrome staining, and in situ digestion with restriction endonucleases. Heredity, 66, 403-409.

MAYR, B. KALAT, M. AND RAB, P. 1988. Heterochromatins and band karyotypes in three species of salmonids. Theor. Appl. Genet., 76, 45-53.

MAYR, B. RAB, P. AND KALAT, M. 1986a. Localisation of NORs and counterstain-enhanced fluoroscence studies in Salmo gairdneri and Salmo trutta (Pisces, Salmonidae). Theor. Appl. Genet., 71, 703-707.

MAYR, B. RAB, P. AND KALAT, M. 1986b. NORs and counterstainenhanced fluorescence studies in Cyprinidae of different ploidy level. Genetica, 69, 11-118.

MORENO, F. J. RODRIGO, R. M. AND GARCIA-HERDUGO, G. 1990. $\mathrm{Ag}-\mathrm{NOR}$ proteins and rDNA transcriptional activity in plant cells. J. Histochem. Cytochem., 38, 1879-1887.

OHNO, s. 1970. Mechanisms of gene duplication. In: Evolution by Gene Duplication, part 4, Springer-Verlag, Berlin, pp. 89-109.

PHILLIPS, R. B. AND IHSSEN, P. E. 1985. Chromosome banding in salmonid fish: nucleolar organizer regions in Salmo and Salvelinus. Can. J. Genet. Cytol., 27, 433-440.

PHillips, R. B., Pleyte, K. A. AND hartley, s. E. 1988. Stockspecific differences in the number and chromosome positions of the nucleolar organizer regions in arctic char (Salvelinus aplinus). Cytogenet. Cell Genet., 48, 9-12.
PHILliPS, R. B., PLEYTE, K. A., VAN, ERT, L. M. AND HARTLEY, S. E. 1989. Evolution of nucleolar organizer regions and ribosomal RNA genes in Salvenlinus. Physiol. Ecol. Japan, 1, 429-447.

PHILlips, R. B., ZAJICEK, K. D. AND UTTER, F. M. 1986a. Chromosome banding in salmonid fishes: nucleolar organizer regions in Oncorhynchus. Can. J. Genet. Cytol., 28, 502-510.

PHILLIPS, R. B., ZAJICEK, K. D., IHSSEN, P. E. AND JOHNSON, O. 1986b. Applications of silver staining to the identification of triploid fish cells. Aquaculture, 54, 313-319.

POPODI, E. M., GREVE, D., PHILLIPS, R. B. AND WEJKSNORA, P. J. 1985. The ribosomal RNA genes of three salmonid species. Biochem. Genet., 23, 997-1010.

SÁNCHEZ, L., MARTÍNEZ, P., VIÑAS, A. AND BOUZA, C. 1990. Analysis of the structure and variability of nucleolar organizer regions of Salmo trutta by $\mathrm{C}-\mathrm{Ag}$ and restriction endonuclease banding. Cytogenet. Cell. Genet., 54, 6-9.

SCHMID, M., LÖSER, C., SCHMIDTKE, J. AND ENGEL, w. 1982. Evolutionary conservation of a common pattern of activity of nucleolus organizers during spermatogenesis in vertebrates. Chromosoma, 86, 149-179.

SCHMIDTKE, J., ZENZES, M. T., WEILER, C. BROSS, K. AND ENGEL, W. 1976. Gene action in fish of tetraploid origin. IV. Ribosomal DNA amount in clupeoid and salmonoid fish. Biochem. Genet., 14, 293.

SCHWEIZER, D. 1976. Reverse fluorescent chromosome banding with chromomycin and DAPI. Chromosoma, 58, 307-324.

SCHWEIZER, D. 1979. Fluorescent chromosome banding in plants: applications, mechanism, and implications for chromosome structure. In: Proceedings of the 4th John Innes Symposium, John Innes Institute, Norwich, U.K, pp. 61-72.

STOCKERT, J. C., FREZqUEZ, C. AND LENTzios, G. 1976. Banding studies on the polytene chromosome of Rynchosciara hollaenderi. Chromosoma., 68, 337-356.

THOMPSON, W. F. AND FLAVELL, R. B. 1988. DNase sensitivity of ribosomal RNA genes in chromatin and nucleolar dominance in wheat. J. Mol. Biol., 204, 535-548.

THORGAARD, G. H. 1986. Ploidy manipulation and performance. Aquaculture, 57, 57-64. 